\title{
Remoção de cádmio a partir da argila de Toritama (estado de Pernambuco) ativada termicamente em sistema de banho finito
}

\section{(Removal of cadmium from thermally activated Toritama (Pernambuco state, Brazil) clay under finite bath conditions)}

\author{
M. L. P. Silva ${ }^{1}$ M. G. F. Rodrigues ${ }^{1}$, M. G. C. Silva ${ }^{2}$ \\ ${ }^{1}$ Unidade Acadêmica de Engenharia Química, Centro de Ciências e Tecnologia, Universidade Federal de \\ Campina Grande - UFCG, Av. Aprígio Veloso 882, Campina Grande, PB 58109-970 \\ ${ }^{2}$ Departamento de Termofluidodinâmica, Faculdade de Engenharia Química, Universidade Estadual de \\ Campinas - UNICAMP, Cidade Universitária Zeferino Vaz, C.P. 6066, Campinas, SP 13081-970 \\ meiry@deq.ufcg.edu.br
}

\begin{abstract}
Resumo
Este trabalho tem como objetivo caracterizar a argila de Toritama, estado de Pernambuco, na sua forma "in natura" após ativação térmica a $500{ }^{\circ} \mathrm{C}$ visando sua utilização na remoção de $\mathrm{Cd}^{2+}$. A argila "in natura" foi caracterizada por meio de espectrometria de raios $\mathrm{X}$ por energia dispersiva (EDX), difração de raios X e análise textural usando adsorção física de nitrogênio (BET). As argilas ativadas termicamente $\left(100,200,300,400\right.$ e $\left.500{ }^{\circ} \mathrm{C}\right)$ foram caracterizadas por difração de raios X. A argila ativada termicamente a $500{ }^{\circ} \mathrm{C}$ foi caracterizada por EDX e BET. A remoção do $\mathrm{Cd}^{2+}$ pela argila ativada termicamente foi realizada em sistema de banho finito. O tratamento térmico modificou levemente a área, como mostrou a análise de área de superfície específica, mas não modificou a distribuição de diâmetro de poros. Os dados experimentais para o sistema de banho finito se ajustaram aos modelos estudados, Langmuir e Freundlich; no entanto, o modelo de Freundlich foi mais satisfatório. O processo de remoção de cádmio em sistema de banho finito pela argila de Toritama ativada termicamente a $500{ }^{\circ} \mathrm{C}$ só atinge o equilíbrio depois de 120 min e apresenta um percentual de cerca de $86,8 \%$ de remoção de cádmio.
\end{abstract}

Palavras-chave: tratamento térmico, caracterização, argilas, metais pesados, adsorção.

Abstract

The purpose of this study is to characterize the clay of Toritama (Pernambuco, Brazil), in its form "in nature", and also after thermal activation at $500{ }^{\circ} \mathrm{C}$, aiming its use in the removal of $\mathrm{Cd}^{2+}$. The clay "in nature" was characterized byg $X$-ray spectrometry by dispersive energy (EDX), X-ray diffraction (XRD), and surface area measurement by physical adsorption of nitrogen (BET). The thermally activated clay $\left(100,200,300,400\right.$ e $\left.500{ }^{\circ} \mathrm{C}\right)$ was characterized by XRD. The thermally activated clay $\left(500{ }^{\circ} \mathrm{C}\right)$ was characterized by EDX and surface area measurement (BET). The removal of $C d^{2+}$ by the thermally activated clay was carried out in a finite bath system. The thermal treatment of the clays slightly modified their area but did not change the pore diameters distribution. The experimental data for the finite bath system could be adjusted to both the studied adsorption isotherm models, Langmuir and Freundlich. However the Freundlich model was more satisfactory. The process of cadmium removal, in finite bath system, for thermally activated clay $\left(500{ }^{\circ} \mathrm{C}\right)$ reaches the equilibrium after $120 \mathrm{~min}$ and presents about $86.8 \%$ of cadmium removal.

Keywords: thermally treatment, characterization, clays, heavy metal, adsorption.

\section{INTRODUÇÃO}

O acelerado desenvolvimento industrial ocorrido nos últimos anos tem gerado graves problemas ambientais. Devido a atual preocupação com o bem estar funcional do meio ambiente, de forma que este desenvolvimento possa ser compatível com a preservação dos recursos naturais, novas técnicas de tratamento de efluentes se fazem necessárias, afim de que seja possível aliar baixos custos à eficiência e à preservação ambiental [1].
A poluição química de natureza inorgânica, originada principalmente pela presença de efluentes contendo metais pesados, é atualmente um dos mais sérios problemas na área ambiental [2-4]. Os metais pesados são tóxicos, até mesmo em baixíssimas concentrações, e não são compatíveis com a maioria dos tratamentos biológicos, destacando-se, então, a possibilidade da descarga deste efluente na rede pública para tratamento conjunto com o esgoto doméstico.

A remoção de metais pesados de efluentes industriais pode ser obtida através da utilização de diversos processos, tais como: precipitação por via química, adsorção em carvão 
ativo, ultra-filtração, osmose reversa e troca iônica, dentre outros [5]. O processo de adsorção tem se tornado o método preferido para remoção de metais pesados [6].

Como termo de granulometria, fração argila é aquela que contém as partículas de menores diâmetros, geralmente inferiores a $2 \mu \mathrm{m}$ [7]. As argilas têm sido extensamente empregadas como adsorventes na remoção de metais pesados [8-15].

Este trabalho faz parte de uma série que vem pesquisando a caracterização de argilas nacionais, visando seu potencial como adsorventes na remoção de metais pesados [16-20]. Este estudo foi realizado para caracterizar uma argila de Toritama (estado de Pernambuco) "in natura" bem como ativada termicamente a $500{ }^{\circ} \mathrm{C}$ visando sua utilização em sistema de banho finito como adsorvente. As argilas "in natura" foram caracterizadas por espectrometria de raios X por energia dispersiva, difração de raios X e adsorção física de nitrogênio (método BET) e as argilas ativadas termicamente $\left(100,200,300,400\right.$ e $\left.500{ }^{\circ} \mathrm{C}\right)$ foram caracterizadas por difração de raios X. A argila ativada termicamente a $500{ }^{\circ} \mathrm{C}$ foi caracterizada por espectrometria de raios $\mathrm{X}$ por energia dispersiva e por adsorção física de nitrogênio (método BET). O objetivo geral é verificar a potencialidade de utilização da argila de Toritama como adsorvente.

\section{EXPERIMENTAL}

A argila foi moída e separada através da técnica de peneiração. A peneiração é uma técnica de separação de materiais sólidos, baseada exclusivamente no tamanho das partículas. O material é colocado em um conjunto de peneiras de diversas aberturas, passando uma parte e ficando outra retida; o diâmetro das partículas pode ser obtido através da média dos diâmetros das peneiras, entre as quais o material está retido.

$$
\overline{\mathrm{dp}}=\frac{\mathrm{d}_{\text {sup }}+\mathrm{d}_{\mathrm{inf}}}{2}(\mathrm{~mm})
$$

As argilas foram utilizadas na faixa granulométrica 3548 mesh com diâmetro de partícula médio $0,358 \mathrm{~mm}$.

Tratamento térmico e caracterização da argila Observou-se em ensaios preliminares que quando em solução aquosa e submetida à agitação, a argila "in natura" se dissolvia parcialmente. A solução empregada (solução de concentração $1 \mathrm{~g} / \mathrm{L}$ de nitrato de cádmio) não ataca a argila mesmo antes da calcinação. No entanto como foi observado experimentalmente ocorre a dissolução parcial da argila não calcinada na solução aquosa do cádmio. A dissolução parcial da argila pode indicar a presença de fases solúveis que não são os argilominerais. Portanto foi realizado um tratamento térmico nas argilas visando torná-las mecanicamente mais estáveis. As amostras foram submetidas ao processo de calcinação em mufla a diferentes temperaturas entre $100 \mathrm{e}$ $500{ }^{\circ} \mathrm{C}$ por $24 \mathrm{~h}$, sendo que a argila de Toritama tornou-se mecanicamente mais estável (não apresentou dissolução) após a calcinação a $500{ }^{\circ} \mathrm{C}$, tendo sido esta temperatura escolhida para o tratamento, e a argila calcinada utilizada no processo de remoção do cádmio. A argila foi submetida às caracterizações com granulometria 200 mesh.

Espectrometria de raios $X$ por energia dispersiva (EDX) - $\mathrm{O}$ equipamento utilizado foi um espectrômetro de raios $\mathrm{X}$ por energia dispersiva EDX-700 Shimadzu.

Difração de raios $X(D R X)$ - O aparelho utilizado foi Shimadzu modelo XDR 6000 com radiação Ka do cobre, com tensão de operação $40 \mathrm{kV}$, corrente $40 \mathrm{~mA}$, com passo de $0,02(2 \theta)$ e tempo por passo de $1 \mathrm{~s}$.

Adsorção física de nitrogênio (método BET) - A área superficial da argila, bem como as isotermas de fisissorção, foram obtidas por fisissorção de nitrogênio $\left(\mathrm{N}_{2}\right)$ (método $\mathrm{BET}$ ) na temperatura do $\mathrm{N}_{2}$ líquido. Esta análise foi realizada em um equipamento BET Gemini III 2375 Surface Area Analyzer da Micromeritics.

Preparação da solução de nitrato de cádmio - Foi preparada uma solução de nitrato de cádmio com $\mathrm{Cd}\left(\mathrm{NO}_{3}\right)_{2}$ (Merck) e água destilada, a uma concentração de 1000 ppm, tendo sido preparadas por diluição desta, as soluções nas concentrações definidas para os ensaios.

Quantificação do cádmio - O equipamento utilizado foi um espectrofotômetro de absorção atômica Perkin Elmer Analyst 100.

Isotermas de equilibrio para a argila ativada a $500{ }^{\circ} \underline{C}$ em sistema de banho finito - Os ensaios foram realizados colocando-se $100 \mathrm{~mL}$ de solução de nitrato de cádmio, com concentrações entre 20 e 200 ppm, em erlenmeyers de $125 \mathrm{~mL}$ contendo $1 \mathrm{~g}$ de argila bentonítica, e mantidos sob agitação por $5 \mathrm{~h}$ com pH controlado em 4,5 e temperatura de $27^{\circ} \mathrm{C}$ de forma a garantir o equilíbrio do sistema. Para controlar o pH foi adicionado sempre que necessário ácido clorídrico e/ou hidróxido de sódio a 0,1 M. Decorrido o tempo do ensaio, as soluções foram centrifugadas, visando a total retirada do sólido para então ser realizada a análise por espectrofotometria de absorção atômica. Foram realizados ensaios com a argila ativada termicamente a $500{ }^{\circ} \mathrm{C}$, e as percentagens de remoção (\%Rem), bem como a capacidade de remoção foram obtidas através das seguintes fórmulas, respectivamente:

$$
\begin{aligned}
& \% \operatorname{Rem}=\left(\frac{\mathrm{C}_{0}-\mathrm{C}}{\mathrm{C}_{0}}\right) * 100 \\
& \mathrm{q}_{\mathrm{eq}}=\frac{\mathrm{V}}{\mathrm{m}}\left(\mathrm{C}_{0}-\mathrm{C}_{\mathrm{eq}}\right)
\end{aligned}
$$

onde $\mathrm{C}_{0}$ : concentração inicial (ppm); C: concentração final (ppm); V: volume de solução (L); m: massa de adsorvente (g); $\mathrm{C}_{\mathrm{eq}}$ : concentração no equilíbrio (ppm).

Testes cinéticos para a argila ativada a $500^{\circ} \mathrm{C}$ em sistema de banho finito - Foram utilizados sistemas de banhos finitos na realização dos testes cinéticos, com as condições de $\mathrm{pH}$ utilizadas nos ensaios anteriores e com a concentração que 
forneceu a melhor percentagem de remoção de cádmio pela argila de ativada termicamente a $500{ }^{\circ} \mathrm{C}$. O experimento consistiu em manter sob agitação constante em um béquer de $250 \mathrm{~mL}$, a temperatura constante de $27^{\circ} \mathrm{C}$ e $\mathrm{pH}$ de 4,5 , uma mistura na proporção de 1/100 massa de argila/volume de solução de nitrato de cádmio. Visando estudar a cinética de remoção, foram coletadas alíquotas de $2 \mathrm{~mL}$ de solução, em intervalos de tempos de 1/4/8/12/16/20/30/40/50/60/9 0/120/150/180/210/240 min, para a obtenção da curva de concentração de cádmio em função do tempo de remoção, a fim de avaliar o tempo de equilíbrio.

\section{RESULTADOS E DISCUSSÃO}

\section{Caracterização}

Os resultados das análises químicas, expressos em óxidos, das argilas: "in natura" e ativadas termicamente a $500{ }^{\circ} \mathrm{C}$ foram obtidas por EDX, conforme a Tabela I.

Tabela I - Composição química das argilas: "in natura" e ativada termicamente a $500^{\circ} \mathrm{C}$ obtidos através do EDX.

[Table I - Chemical composition of clays without treatment and thermally activated $\left(500{ }^{\circ} \mathrm{C}\right)$ by EDX.]

\begin{tabular}{ccc}
\hline Elemento & "In natura" $(\%)$ & Ativada a $500{ }^{\circ} \mathrm{C}(\%)$ \\
\hline $\mathrm{SiO}_{2}$ & 49,14 & 49,37 \\
$\mathrm{Al}_{2} \mathrm{O}_{3}$ & 26,18 & 27,24 \\
$\mathrm{Fe}_{2} \mathrm{O}_{3}$ & 10,66 & 9,79 \\
$\mathrm{~K}_{2} \mathrm{O}$ & 6,22 & 5,91 \\
$\mathrm{MgO}$ & 3,01 & 2,64 \\
$\mathrm{CaO}$ & 2,08 & 1,79 \\
$\mathrm{Na}_{2} \mathrm{O}$ & 1,28 & 1,74 \\
$\mathrm{TiO}_{2}$ & 0,52 & 0,73 \\
$\mathrm{P}_{2} \mathrm{O}_{5}$ & 0,13 & 0,10 \\
$\mathrm{MnO}$ & 0,12 & 0,08 \\
\hline
\end{tabular}

Os componentes mais abundantes nestas amostras são $\mathrm{SiO}_{2}$ e $\mathrm{Al}_{2} \mathrm{O}_{3}$, perfazendo assim mais de $65 \%$. Provavelmente são provenientes dos minerais argilosos e da sílica livre presentes nas amostras [21]. Com relação aos teores de $\mathrm{Fe}_{2} \mathrm{O}_{3}$, são provavelmente provenientes do reticulado cristalino dos argilominerais do grupo da esmectita.

A Fig. 1 apresenta os difratogramas de raios $\mathrm{X}$ das argilas: "in natura" e ativadas termicamente.

O difratograma da argila "in natura" apresenta os picos característicos da montmorilonita (M) e do quartzo (Q), principal componente da argila [21-24]. Modificações estruturais foram obtidas após a ativação térmica da argila como pode ser evidenciado pelas análises de difração de raios $\mathrm{X}$. Verifica-se que o processo de ativação térmica provoca diminuição da intensidade do pico característico da esmectítica e aumento do pico característico do quartzo.

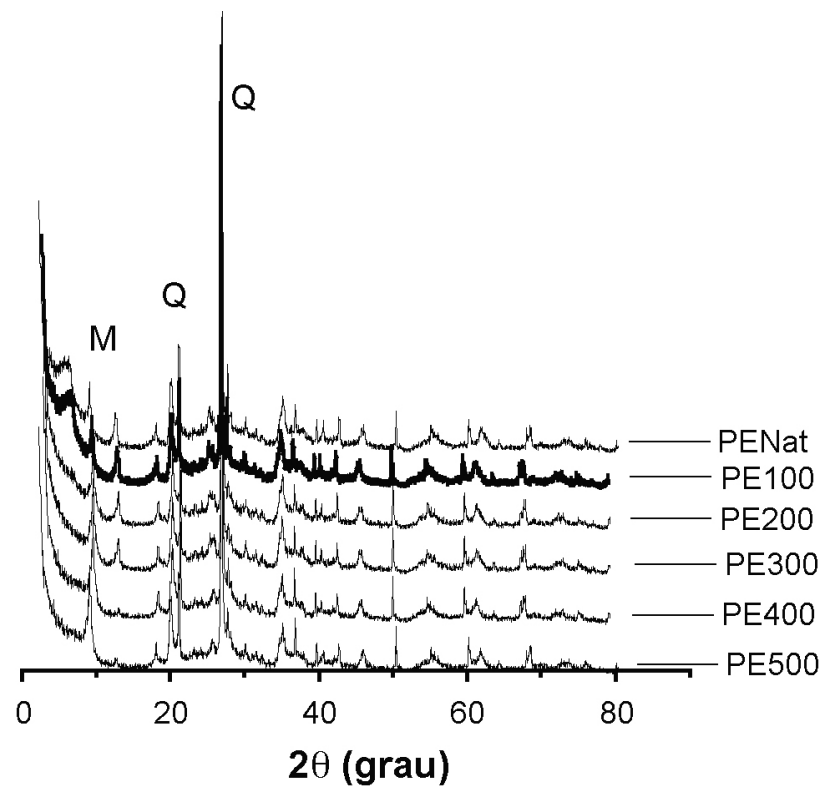

Figura 1: Difratogramas de raios X das argilas "in natura" e ativada termicamente $\left(500^{\circ} \mathrm{C}\right)$.

[Figure 1: X-ray diffraction patterns of clay without treatment and thermally activated $\left(500^{\circ} \mathrm{C}\right)$.]

Este comportamento pode ser explicado possivelmente por uma re-organização da estrutura da argila.

Os resultados obtidos para a área de superfície específica das argilas "in natura" quanto ativada termicamente a $500{ }^{\circ} \mathrm{C}$ encontram-se na Tabela II.

Com relação aos resultados da argila "in natura", há

Tabela II - Área de superfície específica das argilas "in natura" ativada termicamente a $500{ }^{\circ} \mathrm{C}$, obtida por adsorção de $\mathrm{N}_{2}$ (método BET).

[Table II - Specific surface area of clays without treatment and thermally activated clay $\left(500^{\circ} \mathrm{C}\right)$ by $\mathrm{N}_{2}$ adsorption (BET method).]

\begin{tabular}{cc}
\hline Argila de Toritama & Área Superficial $\left(\mathrm{m}^{2} / \mathrm{g}\right)$ \\
\hline "in natura" & 63 \\
Ativada a $500{ }^{\circ} \mathrm{C}$ & 59 \\
\hline
\end{tabular}

uma pequena modificação no valor da área após a ativação térmica. Examinando os resultados da área específica da argila ativada termicamente a $500{ }^{\circ} \mathrm{C}$, nota-se que ocorre uma pequena diminuição de $3 \%$ em relação a argila "in natura" [25-26].

A distribuição de poros das argilas "in natura" e ativada termicamente a $500{ }^{\circ} \mathrm{C}$ estão apresentados na Tabela III.

O processo de ativação térmica não provocou modificação drástica na distribuição de poros, confirmando que o tratamento térmico efetivamente não alterou as condições de porosidade da argila [27]. Este fato dá subsídios para que 
Tabela III - Distribuição de poros das argilas "in natura" e ativada termicamente a $500{ }^{\circ} \mathrm{C}$.

[Table III - Distribution of pores of clay without treatment and thermally activated clay $\left.\left(500^{\circ} \mathrm{C}\right).\right]$

\begin{tabular}{cccc}
\hline \multicolumn{2}{c}{ Argila “in natura” } & \multicolumn{2}{c}{$\begin{array}{c}\text { Argila ativada termicamente } \\
\text { a } 500{ }^{\circ} \mathrm{C}\end{array}$} \\
\hline $\begin{array}{c}\text { Faixa de } \\
\text { diâmetros } \\
(\AA)\end{array}$ & $\begin{array}{c}\text { diâmetro } \\
\text { médio } \\
(\AA)\end{array}$ & $\begin{array}{c}\text { faixa de } \\
\text { diâmetros }(\AA)\end{array}$ & $\begin{array}{c}\text { diâmetro } \\
\text { médio } \\
(\AA)\end{array}$ \\
\hline $1334,3-219,9$ & 245,8 & $1231,1-216,2$ & 243,1 \\
$219,9-105,4$ & 124,8 & $216,2-104,0$ & 123,3 \\
$105,4-68,5$ & 78,7 & $104,0-67,9$ & 78,1 \\
$68,5-50,1$ & 56,1 & $67,9-49,3$ & 55,4 \\
$50,1-38,5$ & 42,6 & $49,3-37,8$ & 41,9 \\
$38,5-30,5$ & 33,5 & $37,8-29,8$ & 32,7 \\
$30,5-24,4$ & 26,7 & $29,8-23,7$ & 25,9 \\
$24,4-21,8$ & 22,9 & $23,7-21,0$ & 22,2 \\
$21,8-19,3$ & 20,4 & $21,0-18,6$ & 19,7 \\
$19,3-17,4$ & 18,3 & $18,6-16,7$ & 17,5 \\
\hline
\end{tabular}

a argila ativada termicamente a $500{ }^{\circ} \mathrm{C}$ possa ser usada no processo de sistema de banho finito.

Os resultados de percentual e capacidade de remoção de cádmio, obtidos com os ensaios em sistema de banho finito, para a argila ativada termicamente a $500{ }^{\circ} \mathrm{C}$ encontram-se na Tabela IV.

A capacidade de remoção aumenta para maiores valores de concentração de cádmio na solução. A argila ativada termicamente a $500{ }^{\circ} \mathrm{C}$ apresenta um máximo para a capacidade de remoção de $6,18 \mathrm{mg}$ de cádmio/g de argila para a concentração da solução de 185,5 ppm de cádmio. Com relação à percentagem de remoção, a argila ativada termicamente a $500{ }^{\circ} \mathrm{C}$ atinge $82,17 \%$ de remoção de cádmio para a concentração da solução de 18,47 ppm de cádmio. Verifica-se ainda que argila ativada termicamente a $500{ }^{\circ} \mathrm{C}$ apresenta uma remoção mínima de apenas $34 \%$ para

Tabela IV - Resultados da percentagem e da capacidade de remoção da argila ativada termicamente a $500{ }^{\circ} \mathrm{C}$.

[Table IV - Results of the percentage and the capacity of removal of the thermally activated clay $\left(500{ }^{\circ} \mathrm{C}\right)$.]

\begin{tabular}{ccc}
\hline $\begin{array}{c}\text { Concentração } \\
\text { Inicial } \\
(\mathrm{mg} / \mathrm{L})\end{array}$ & \%Removida & $\begin{array}{c}\text { Capacidade } \\
\text { de remoção } \\
(\mathrm{mg} / \mathrm{g})\end{array}$ \\
\hline 18,47 & 82,17 & 1,52 \\
62,81 & 58,59 & 3,68 \\
107,67 & 48,55 & 5,23 \\
149,85 & 42,90 & 6,43 \\
185,52 & 33,99 & 6,18 \\
\hline
\end{tabular}

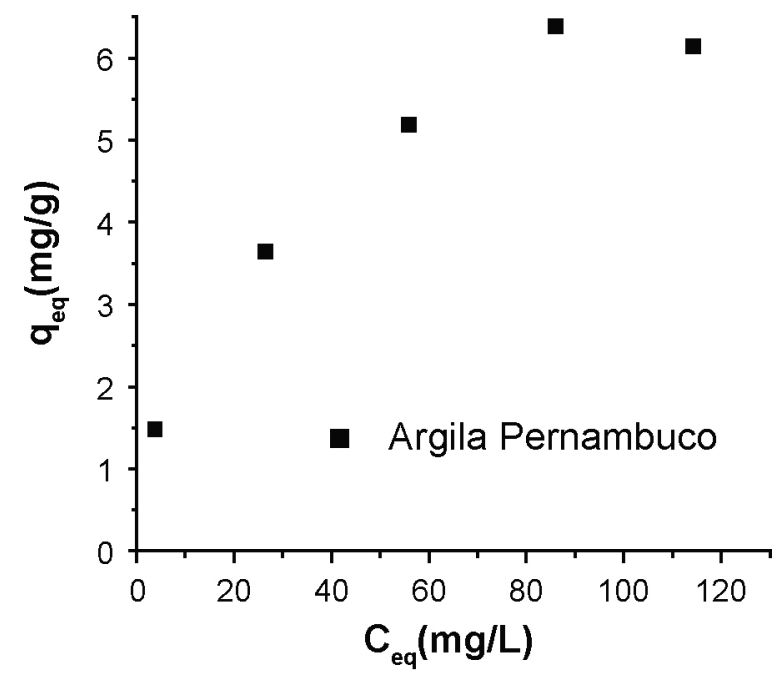

Figura 2: Isoterma de adsorção de cádmio para argila ativada termicamente a $500{ }^{\circ} \mathrm{C}$.

[Figure 2: Adsorption isotherms of cadmium by thermally treated activated clay $\left(500{ }^{\circ} \mathrm{C}\right)$.]

a concentração de 185,5 ppm.

A Fig. 2 apresenta a isoterma de remoção de cádmio em sistema de banho finito para a argila ativada termicamente a $500{ }^{\circ} \mathrm{C}$.

A argila ativada termicamente a $500{ }^{\circ} \mathrm{C}$ apresenta capacidade de remoção de $4,5 \mathrm{mg}$ de metal/g de adsorvente para um valor de concentração de equilíbrio de $40 \mathrm{ppm}$. A isoterma para a argila ativada termicamente a $500{ }^{\circ} \mathrm{C}$ foi linearizada tanto para o modelo de Freundlich dado pela Equação D e sua forma linearizada (Equação E) quanto para o modelo de Langmuir dado pela Equação $\mathrm{F}$ e sua forma linearizada (Equação G).

O primeiro modelo empírico foi desenvolvido por Freundlich em 1926. A sua forma é dada pela Equação D.

$$
\mathrm{q}_{\mathrm{eq}}=\mathrm{kC}_{\mathrm{e}} \mathrm{e}^{1 / n}
$$

onde $\mathrm{q}_{\mathrm{eq}}$ : quantidade de soluto adsorvido por unidade de massa (mg de metal/g de adsorvente); $\mathrm{C}_{\mathrm{e}}$ : concentração de soluto na fase líquida em equilíbrio com a fase sólida (ppm); n: constante da equação de Freundlich; k: constante de Freundlich.

Essa expressão pode ser linearizada sob a forma da Equação E.

$$
\log \mathrm{q}_{\mathrm{eq}}=\log \mathrm{k}+\frac{1}{\mathrm{n}} \log \mathrm{C}_{\mathrm{e}}
$$

Ainda hoje esse modelo é considerado um dos que possuem melhor ajuste em termos de modelos empíricos [28].

Entre os modelos representativos dessas relações de equilíbrio, o mais utilizado é o de Langmuir, que ocorre geralmente quando a natureza de interação do adsorbato com a fase sólida é química. No modelo de Langmuir, consideram-se as seguintes hipóteses: A superfície é 
assumida como sendo homogênea, ou seja, composta por somente um tipo de sítio de adsorção; As espécies metálicas adsorvidas interagem somente com um tipo de sítio ativo de forma que cada sítio pode acomodar somente uma molécula e que haja formação de uma monocamada; A adsorção é limitada à monocamada; Assume-se que não haja competição de espécies a serem adsorvidas, de forma que apenas uma pode ser adsorvida; A energia de adsorção é idêntica em todos os sítios ativos e independe da presença de espécies adsorvidas em sítios ativos vizinhos; A solução carregada de espécies metálicas é diluída; $O$ processo de adsorção ocorre de forma reversível. A expressão matemática representativa da isoterma de Langmuir é dada pela Equação F:

$$
\mathrm{q}_{\mathrm{eq}}=\frac{\mathrm{q}_{\mathrm{m}} \mathrm{C}_{\mathrm{e}}}{\mathrm{K}_{\mathrm{d}}+\mathrm{C}_{\mathrm{e}}}
$$
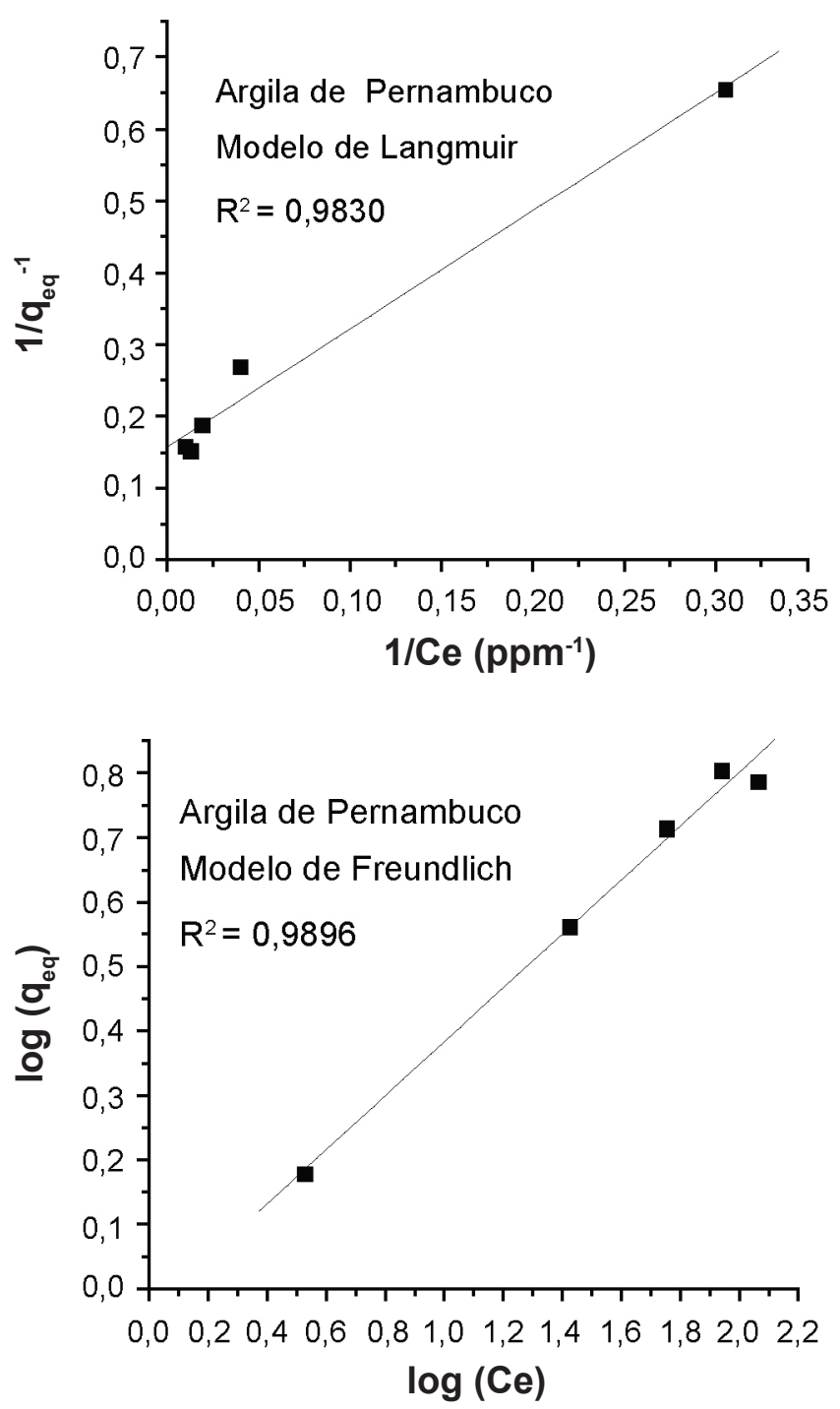

Figura 3: Linearização da isoterma de adsorção de cádmio para argila ativada termicamente a $500^{\circ} \mathrm{C}$.

[Figure 3: The linearized Langmuir and Freundlich plots for cadmium ion sorption for the thermally treated activated clay $\left(500^{\circ} \mathrm{C}\right)$.] onde $\mathrm{q}_{\mathrm{eq}}$ : quantidade de soluto adsorvido por unidade de massa (mg de metal/g de adsorvente); $\mathrm{q}_{\mathrm{m}}$ : capacidade máxima do adsorvente ( $\mathrm{mg}$ de metal/g de adsorvente); $\mathrm{K}_{\mathrm{d}}$ : constante de dissociação efetiva; $\mathrm{C}_{\mathrm{e}}$ : concentração no equilíbrio (ppm).

Verifica-se que os desvios da idealidade do modelo de Langmuir são devidos à heterogeneidade da superfície e/ou interações laterais, ou seja, a superfície apresenta duas ou mais classes de sítios com diferentes afinidades, ou então, à medida que um sítio é ocupado por uma molécula, há uma diminuição ou aumento da probabilidade de que a molécula seguinte possa interagir com um sítio vizinho.

A equação de Langmuir pode ser linearizada por meio de transformações algébricas, (Equação G):

$$
\frac{1}{\mathrm{q}_{\mathrm{eq}}}=\frac{\mathrm{K}_{\mathrm{d}}}{\mathrm{q}_{\mathrm{m}}} \cdot \frac{1}{\mathrm{C}_{\mathrm{e}}}+\frac{1}{\mathrm{q}_{\mathrm{m}}}
$$

Tabela V - Parâmetros obtidos para as equações linearizadas de Langmuir e de Freundlich.

[Table V-Adsorption Isotherm Parameters obtained from linearized equations of Langmuir and Freundlich.]

\begin{tabular}{ccc}
\hline Argila & Langmuir & Freundlich \\
\hline Pernambuco & $\mathrm{q}_{\mathrm{m}}=6,16$ & $\mathrm{k}=0,94$ \\
& $\mathrm{~K}_{\mathrm{d}}=10,13$ & $\mathrm{n}=2,39$ \\
\hline
\end{tabular}

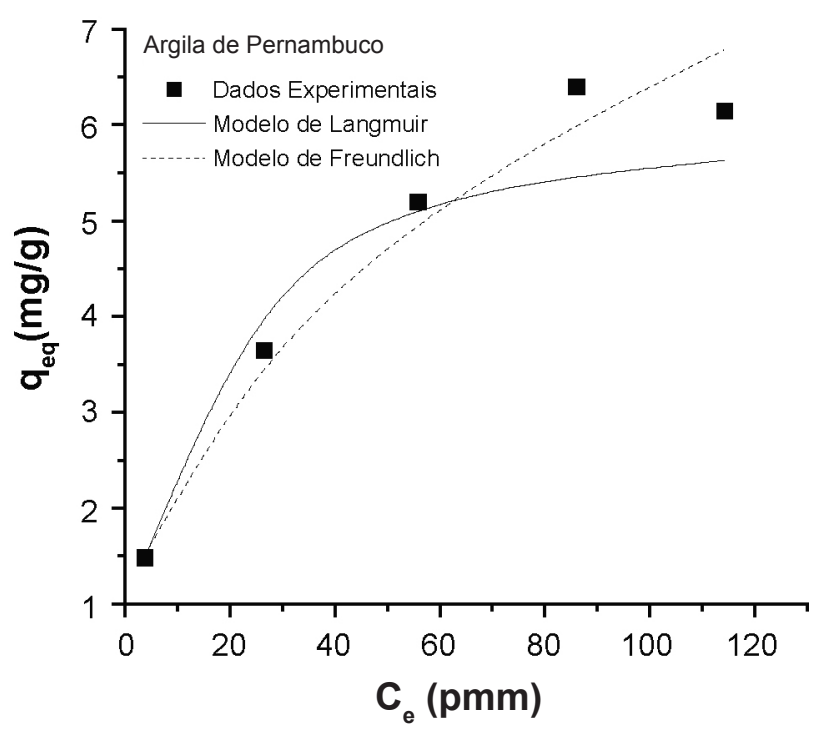

Figura 4: Ajuste dos modelos de Langmuir e de Freundlich aos dados experimentais obtidos com a argila ativada termicamente a $500{ }^{\circ} \mathrm{C}$.

[Figure 4: Fitting of the Langmuir and Freundlich models to the experimental data obtained with the clay thermally activated clay $\left.\left(500{ }^{\circ} \mathrm{C}\right).\right]$ 
Os resultados da linearização encontram-se na Fig. 3.

Os dados se ajustam mais adequadamente ao modelo de Freundilch linearizado para a argila ativada termicamente a $500{ }^{\circ} \mathrm{C}$ como mostram os coeficientes de correlação. Os parâmetros obtidos para as equações linearizadas encontramse na Tabela V.

São apresentados na Fig. 4 os ajustes dos modelos de Langmuir e de Freundlich aos dados experimentais obtidos para a argila ativada termicamente a $500{ }^{\circ} \mathrm{C}$.

Como o ajuste pelo modelo de Freundlich é mais representativo para a argila ativada a $500{ }^{\circ} \mathrm{C}$ tem-se que o modelo que representa o processo de remoção de cádmio, em banho finito, pela argila ativada termicamente a $500{ }^{\circ} \mathrm{C}$ pode ser dado pela seguinte equação $H$ :

$$
\mathrm{q}_{\mathrm{eq}}=0,94 \mathrm{C}_{\mathrm{e}}^{1 / 2,39}
$$

A cinética de remoção de cádmio pela argila ativada termicamente a $500{ }^{\circ} \mathrm{C}$ encontra-se na Figura 5.

É possível verificar que a argila ativada termicamente a $500{ }^{\circ} \mathrm{C}$ apresenta um comportamento com uma rápida remoção de cádmio no início, apresentando uma cinética bem definida, tendo sido removidos $84 \%$ do cádmio nos primeiros $50 \mathrm{~min}$

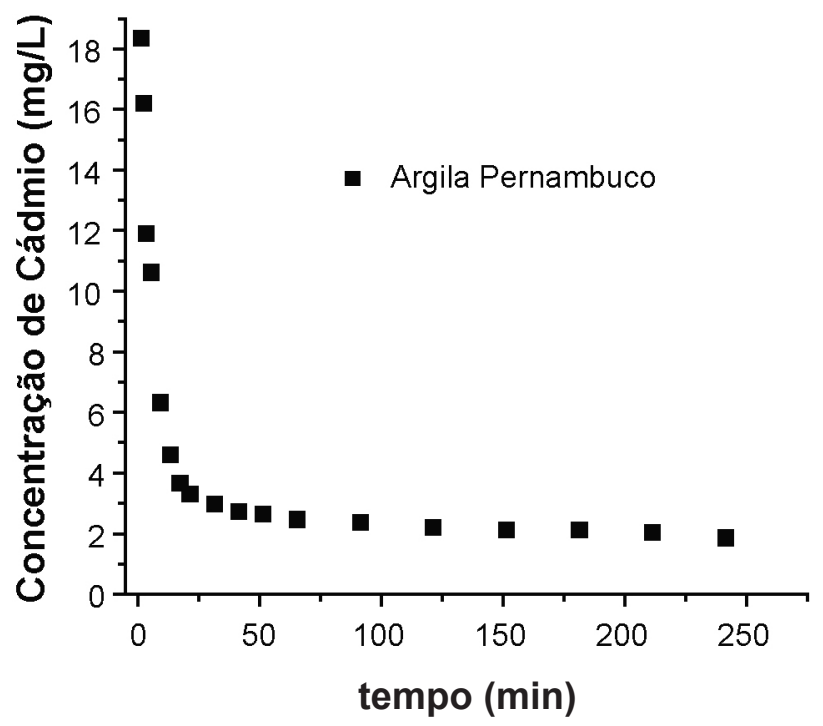

Figura 5: Cinética de adsorção de cádmio para a argila ativada termicamente a $500{ }^{\circ} \mathrm{C}$ com concentração inicial de 18,5 ppm de cádmio.

[Figure 5: Kinetics of adsorption of cadmium for the thermally treated activated clay $\left(500{ }^{\circ} \mathrm{C}\right)$ with initial concentration of 18.5 ppm of cadmium.]

\section{CONCLUSÕES}

A argila ativada termicamente possui capacidade para remover cádmio a partir de efluentes sintéticos.

Foi possível acompanhar por difração de raios $\mathrm{X}$ a evolução da estrutura da argila após tratamentos térmicos $\left(100,200,300,400\right.$ e $\left.500{ }^{\circ} \mathrm{C}\right)$ verificando que não houve colapso de estrutura em nenhuma das temperaturas estudadas, porém houve modificação nos picos característicos (esmectita e quartzo).

O tratamento térmico a $500{ }^{\circ} \mathrm{C}$ a que a argila de Toritama foi submetida provocou uma pequena diminuição da área de superfície especifica, porém não afetou a distribuição de poros.

Para o processo de sistema de banho finito com a argila ativada termicamente a $500{ }^{\circ} \mathrm{C}$ se ajustaram satisfatoriamente ao modelo de Freundlich.

$\mathrm{O}$ equilíbrio do processo de remoção de cádmio pela argila ativada termicamente a $500{ }^{\circ} \mathrm{C}$, em sistema de banho finito, ocorre rapidamente e a argila só atinge o equilíbrio, decorridos 120 minutos de experimento e apresenta um percentual de cerca de $86,78 \%$ de remoção de cádmio.

\section{AGRADECIMENTOS}

Os autores agradecem ao CNPq pela bolsa de mestrado concedida.

\section{REFERÊNCIAS}

[1] C. Pavan, Ciência Hoje 8, 45 (1988) 68-70.

[2] J. H. Potgieter, S. S. Potgieter-Vermaak, P. D. Kalibantonga, Miner. Eng. 19 (2006) 463.

[3] O. Abollino, M. Aceto, M. Malandrino, C. Sarzanini, E. Mentasti, Water Res. 37 (2003) 1619.

[4] M. Malandrino, O. Abollino, A. Giacomino, M. Aceto, E. Mentasti, J. Colloid Interface Sci. 299 (2006) 537.

[5] B. Bayat, J. Hazard. Mater. B 95 (2002) 251.

[6] H. H. Tran, F. A. O’Donnell, Water Res. 33 (1999) 2992.

[7] E. R. Grim, Clay Mineralogy, $2^{\text {nd }}$ Ed., Mc Graw-Hill Book Co. Inc. USA (1968).

[8] F. Cadena, R. Rizvi, R. W. Peters, Hazardous and Industrial Wastes, Proc. $22^{\text {nd }}$ Mid-Atlantic Industrial Waste Conf., Drexel University, USA (1990) 77-94.

[9] S. A. Khan, A. Riaz-ur-Rehman, M. A. Khan, Waste Manag. 15, 4 (1995) 271.

[10] E. G. Pradas, M. V. Sánchez, F. C. Cruz, M. S. Viciana, M. F. Perez J. Chem. Tech. Biotechnol. 59 (1994) 289.

[11] K. P. Yadava, B. S. Tyagi, V. N. Singh, J. Chem. Tech. Biotechnol. 51 (1991) 47.

[12] R. Naseem, S. S. Tahir, Water Res. 35, 16 (2001) 3982.

[13] J. C. Miranda-Trevino, C. A. Coles, Appl. Clay Sci. 23 (2003) 133.

[14] F. Ayari, E. Srasra, M. Trabelsi-Ayadi, Desalination 185 (2005) 391 .

[15] K. G. Bhattacharyya, S. S. Gupta, J. Colloid Interface Sci. 310 (2007) 411.

[16] M. G. F. Rodrigues, M. L. P. D. Silva, M. G. C. D. Silva, Cerâmica 50 (2004) 190.

[17] M. L. P. da Silva, B. V. Sousa, C. F. Sebok, S. J. Kleinubing, M. G. F. Rodrigues, M. G. C. Silva, Anais XVI Cong. Bras. Eng. Quím./III Cong. Bras. Termodinâmica 
Apl. (COBEQ), Santos, SP (2006).

[18] A. F. A. Neto, B. V. Sousa, A. C. C. Andrade, M. G. F. Rodrigues, Anais $6^{\circ}$ Encontro Bras. Adsorção, Maringá, PR (2006).

[19] A. F. A. Neto, S. J. Kleinumbing, M. G. C. Silva, M. G. F. Rodrigues, Anais ENEMP - XXXIII Cong. Bras. Sistemas Particulados, Aracaju, SE (2007).

[20]. A. F. A. Neto, S. J. Kleinumbing, M. G. C. Silva, M. G. F. Rodrigues, Anais VI Encontro SBPMAT, Natal, RN (2007).

[21] M. Hajjaji, S. Kacim, A. Alami, A. El Bouadili, M. El Mountassir, Appl. Clay Sci. 20 (2001) 1.

[22] P. S. Santos, Ciência e Tecnologia de Argilas, 2a Ed., Editora Edgard Blücher, S. Paulo, SP (1992).
[23] R. M. Torres Sánchez, Colloids Surf. A: Physicochem. Eng. Aspects 127 (1997) 135.

[24] C. Volzone, A. M. Césio, Mat. Chem. Phys. 48 (1997) 216.

[25] O. Carmody, R. Frost, Y. Xi, S. Kokot, Surf. Sci. 601 (2007) 2066.

[26] C. J. Mena-Duran, M. R. Sun, T. Lopez, J. A. AzamarBarrios, D. H. Aguilar, M. I. Domínguez, J. A. Odriozola, P. Quintana, Appl. Surf. Sci. 253 (2007) 5762.

[27] S. Chandrasekhar, S. Ramaswamy, Appl. Clay Sci. 21 (2002) 133.

[28] D. M. Ruthven, Principals of Adsorption and Adsorption Processes, John Wiley \& Sons (1984) 436.

(Rec. 20/01/2007, Rev. 18/12/2007, Ac. 12/09/2008) 